\title{
WEARABLE ANTENNAS 3.8 AND 5.6 GHZ USING FOR INDOOR CHILD MONITORING
}

\author{
Dr. Hayder Jawad Mohammed Albattat, \\ Al-Furat Al-Awsat Technical University \\ E-mail: saidhaider75@yahoo.com \\ Hayder.albattat@atu.edu.iq
}

Received on 27 August 2017 Accepted on 31 October 2017 Published on 30 December 2017 DOI: $10.30772 /$ qjes.v10i4.489

\begin{abstract}
In latest years the progress and employment of wearable antennas have developed quickly for human monitoring applications. Due to shrink of wireless communication equipment reasons, the microstrip patch antennas with size-reduced are preferred. In this paper, two wearable antennas with different shapes (similar to the button) are introduced. These are compatible for a commercial wireless system platforms such WiFi and WiMax standards. The proposed antennas are very suitable for child indoor monitoring purposes. Here, because of the small size of these antennas (the largest dimension approaches to $25 \mathrm{~mm}$ ), the assumption of bending the surface, substrate and ground layer are neglected. The operation frequency band for the first antenna is between 5.4 and $5.6 \mathrm{GHz}$, while its between 3.6 to $3.8 \mathrm{GHz}$ for the second and both with a linearly polarized radiation. For a wearable antenna, a conductive textile was used for the substrate layer, a permittivity of 4.4 is used. A 52\% size reduction result of the rose patch size (the $2^{\text {nd }}$ antenna) compared to the size of a regular rectangular patch antenna (the $1^{\text {st }}$ antenna) additionally, investigations had been conducted for different antenna without bending and the antenna's performance in vicinity to human body. The proficient multiphasic COMSOL software is used for simulation.
\end{abstract}

Keywords: Wearable Antenna, patch antenna, Wi-Fi, Wi-Max, WBAN, COMSOL.

\section{INTRODUCTION}

The microstrip patch antennas with size-reduced is favourite for modern wireless applications [1, 2]. These type of antennas is very suitable for wireless body area networks (WBAN). WBAN have increased attention because of their wide applications in civilian and military, which used in medical sensor systems, rescue service applications, military communication or personal entertaining [3]. WBAN's applications in monitoring services have been growing. Many bands of frequencies allocated for WBAN, such the Medical Implant Communication System (MICS) where $400 \mathrm{MHz}$ is used, $2.4 \mathrm{GHz}$ and $5.8 \mathrm{GHz}$ bands for the Industrial Scientific Medical (ISM), low and high frequencies of the Ultra-wideband (UWB) which lie between 3 and $10 \mathrm{GHz}$ band [4-7].

In recent times, rapid increasing wireless equipment encouraged the development of modern wireless standards such WiFi and WiMax [6-7]. Recent communications have characterised the transmission between different antennas located around the body [8]. Wearable antennas have already been developed as metal patches with different shapes on textile fabric [7]. The antennas published in [8] were probe fed and linearly 


\section{AL-QADISIYAH JOURNAL FOR ENGINEERING SCIENCES}

Vol. 10, No. 4

ISSN: $1998-4456$

polarized while later development [8] achieved circular polarization [9] with a microstrip feeding line ensuring higher wearing comfort. More recently, the authors of the present manuscript introduced a wearable button antenna [6]. The rest of this paper is prepared as follows. Section II presents the proposed of antennas geometries. Results and discussion confirmed at the third part of the paper. Lastly, IV part shows the conclusions reached by the work.

\section{GEOMETRIES OF THE DESIGNED ANTENNAS}

Two of geometrical shape of antennas with small size are introduced. The shapes of these antennas are similar to the button, where these entries are very suitable for clothing. The design of these antennas are taking of the base of a substrate square with size of $0.02 \mathrm{~mm}^{2}$ as a wearable one for the child monitoring purpose. The line feeding technique for such type of antenna is microstrip which has been used for the basic circular button microstrip patch antenna. The detail of the dimensions of these aerials are shown in Figure 1 and Figure 2. Glass epoxy (FR\$) as a substrate is used. permittivity constant $\left(\varepsilon_{\mathrm{r}}\right)$ is approached to 4.4 .

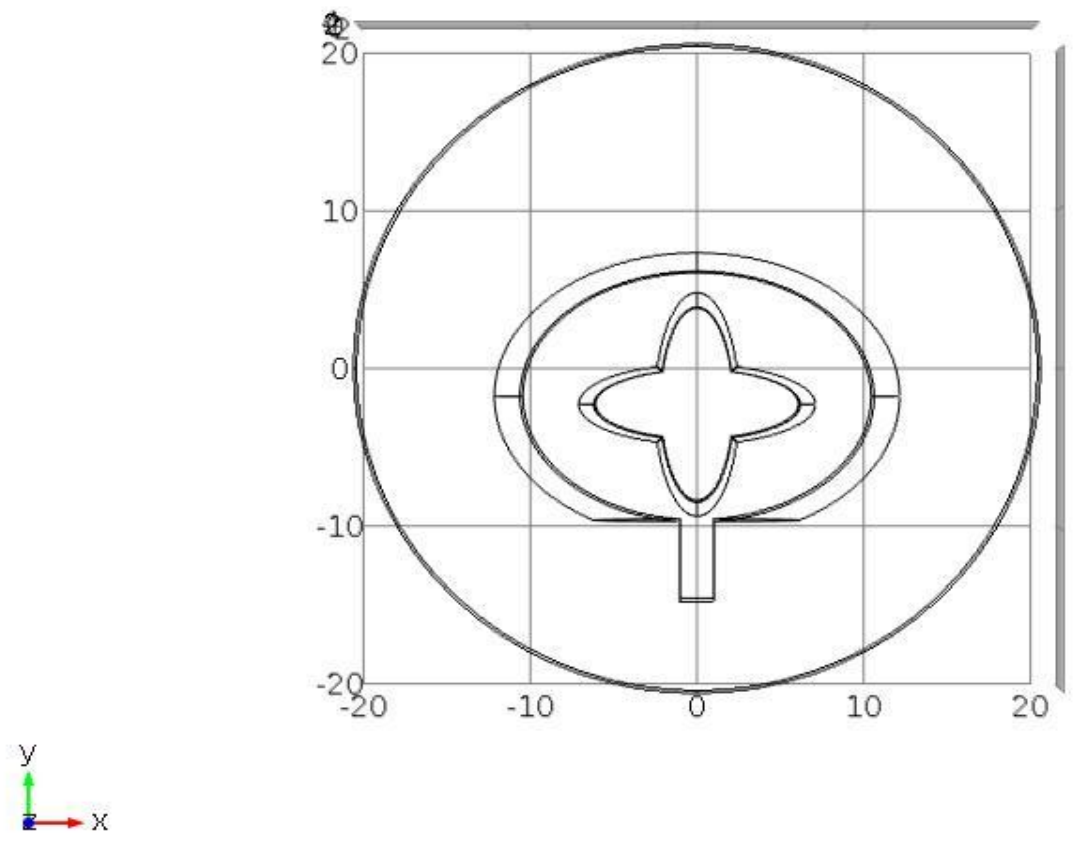

Figure 1: The layout of the proposed antenna No. 1.

The horizontal and vertical views of the first antenna are shown in Figure $\mathbf{3 a}$ and $\mathbf{b}$, respectively. In other side, the horizontal and vertical views of the second antenna are shown in Figure $\mathbf{4 a}$ and $\mathbf{b}$, respectively.

Table 1 and 2 have the geometrical characteristics of the antenna 1 and 2, respectively. 

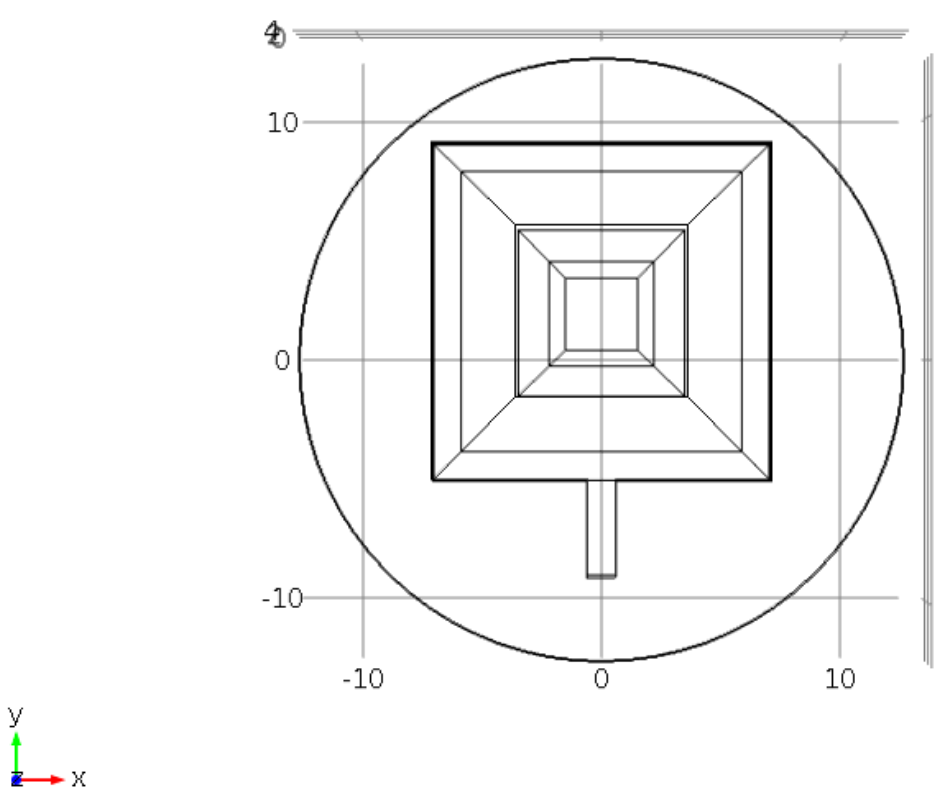

Figure 2: The layout of the proposed antenna no. 2.

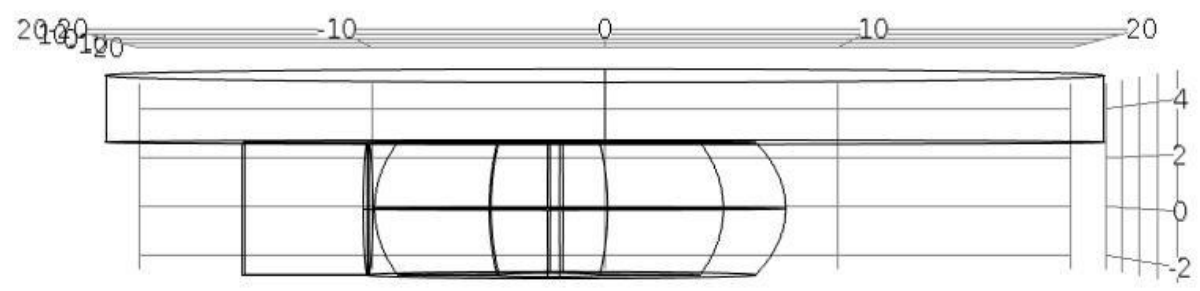

$\prod_{x \rightarrow y}^{z}$

Figure 3 a: Horizontal view of the antenna No.1. 

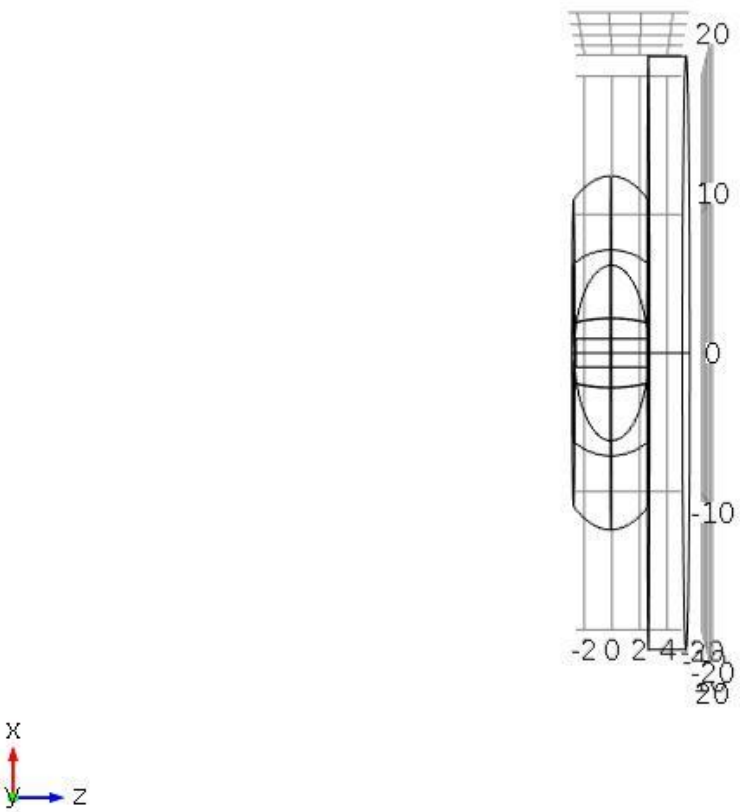

Figure $3 \mathbf{b}$ : The vertical view of the antenna no.1.

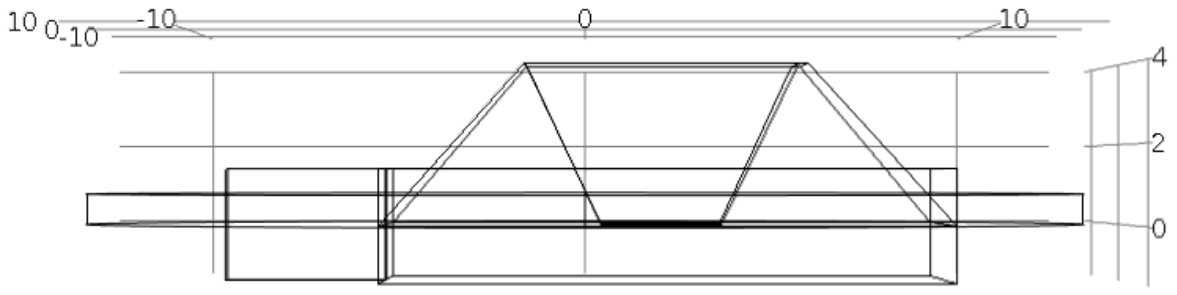

$\stackrel{z}{\longrightarrow} y$

Figure 4 a: Horizontal view of the antenna no.2. 


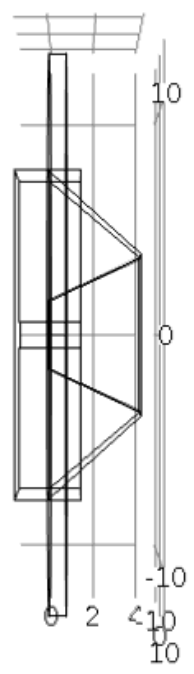

Figure $4 \mathbf{b}$ : The vertical view of the antenna no.2.

Table 1: The dimension characteristics of the first antenna.

\begin{tabular}{|c|c|c|c|}
\hline Name & Expression & Unit & Description \\
\hline$D$ & 5.8 & {$[\mathrm{~mm}]$} & Substrate thickness \\
\hline$W_{\text {line }}$ & 1.13 & {$[\mathrm{~mm}]$} & 50 ohm line width \\
\hline$W_{\text {patch }}$ & 60 & {$[\mathrm{~mm}]$} & Patch width \\
\hline$L_{\text {patch }}$ & 60 & {$[\mathrm{~mm}]$} & Patch length \\
\hline$W_{\text {stub }}$ & 5 & {$[\mathrm{~mm}]$} & Tuning stub width \\
\hline$L_{\text {stub }}$ & 16 & {$[\mathrm{~mm}]$} & Tuning stub length \\
\hline$W_{\text {sub }}$ & 90 & {$[\mathrm{~mm}]$} & Substrate width \\
\hline$L_{\text {sub }}$ & 90 & {$[\mathrm{~mm}]$} & Substrate length \\
\hline$f_{\text {min. }}$ & 2.5 & {$[\mathrm{GHz}]$} & Minimum frequency in sweep \\
\hline$f_{\text {max. }}$ & 4.4 & {$[\mathrm{GHz}]$} & Maximum frequency in sweep \\
\hline$D 1$ & 110 & {$[\mathrm{mil}]$} & Patch thickness \\
\hline$\varepsilon_{\mathrm{r}}$ & & 4.4 \\
\hline$R_{\text {in }}$ & \multicolumn{2}{|c}{50 Ohms } \\
\hline
\end{tabular}




\section{AL-QADISIYAH JOURNAL FOR ENGINEERING SCIENCES}

Vol. 10, No. 4

ISSN: $1998-4456$

Table 2: The dimension characteristics of the second antenna.

\begin{tabular}{|c|c|c|c|}
\hline Name & Expression & Unit & Description \\
\hline $\mathrm{D}$ & 1.5 & {$[\mathrm{~mm}]$} & Substrate thickness \\
\hline$W_{\text {line }}$ & 1.13 & {$[\mathrm{~mm}]$} & 50 ohm line width \\
\hline$W_{\text {patch }}$ & 60 & {$[\mathrm{~mm}]$} & Patch width \\
\hline $\mathrm{L}_{\text {patch }}$ & 60 & {$[\mathrm{~mm}]$} & Patch length \\
\hline$W_{\text {stub }}$ & 5 & {$[\mathrm{~mm}]$} & Tuning stub width \\
\hline $\mathrm{L}_{\text {stub }}$ & 16 & {$[\mathrm{~mm}]$} & Tuning stub length \\
\hline $\mathrm{W}_{\text {sub }}$ & 90 & {$[\mathrm{~mm}]$} & Substrate width \\
\hline$L_{\text {sub }}$ & 90 & {$[\mathrm{~mm}]$} & Substrate length \\
\hline$f_{\min }$. & 1.5 & {$[\mathrm{GHz}]$} & Minimum frequency in sweep \\
\hline$f_{\max }$ & 6.5 & {$[\mathrm{GHz}]$} & Maximum frequency in sweep \\
\hline D1 & 110 & [mil] & Patch thickness \\
\hline$\varepsilon_{\mathrm{r}}$ & & & 4.4 \\
\hline Dim & & & $\mathrm{nm} \times 25 \mathrm{~mm}$ \\
\hline
\end{tabular}

\section{RESULTS AND DISCUSSIONS}

Figure 5 related to the simulated electric field norm for the proposed first antennas. Figure 6 shows the radiation pattern in $2 \mathrm{D}$ for the same antenna. the antennas have a good return loss for $3.6 \mathrm{GHz}$ with respect to less than $-14 \mathrm{~dB}$ as shown in Figure 7. Desired characteristics of WiFi and WiMax is achieved through the first antenna.

It's obvious from Figure 9 that for the resonant frequency of $5.6 \mathrm{GHz}$ the return losses parameter $\mathrm{S}_{11}$ is less than -20 where its very suite to such application with respect to the required quantity of $-10 \mathrm{~dB}$ for such task. Also this frequency is standard frequency for WiFi, and local area requests. The desired frequency component is in band of 5.3 to $5.6 \mathrm{GHz}$. The antenna realizes the required conditions for wireless body purposes.

The two dimensions (2D) far-field [V/m] radiation patterns in of the proposed antenna (see Figure 8), which denotes to the directivity and the gain of the antenna. The intensities of electric field is drawn for the fundamental frequency of our antenna as shown Figure 5. To estimate the energy density per cubic meter through time interval. 


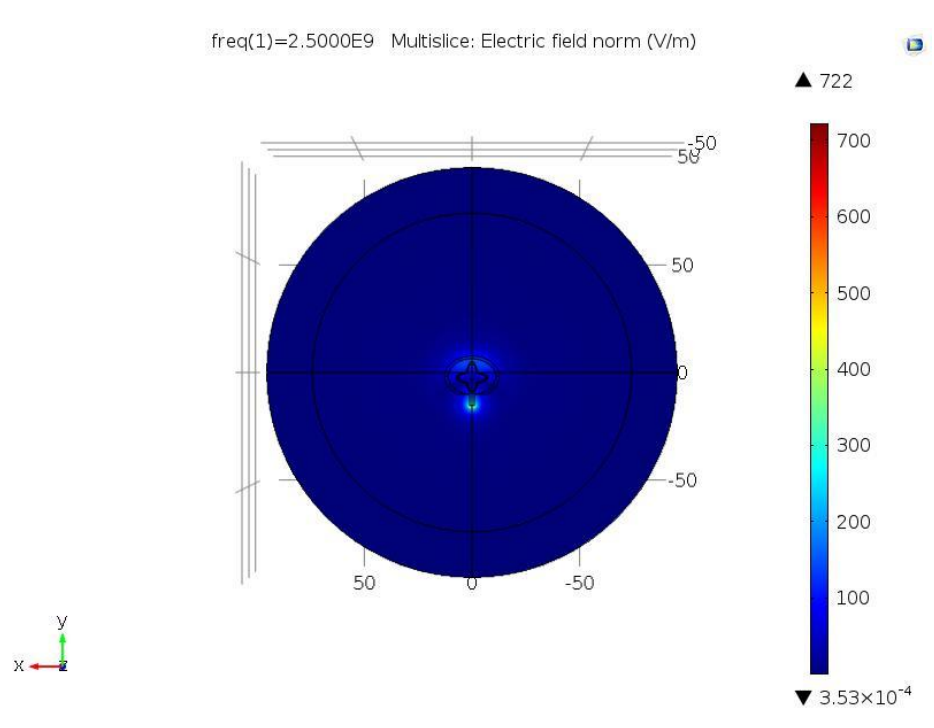

Figure 5: Electric field norm for the proposed first antenna.

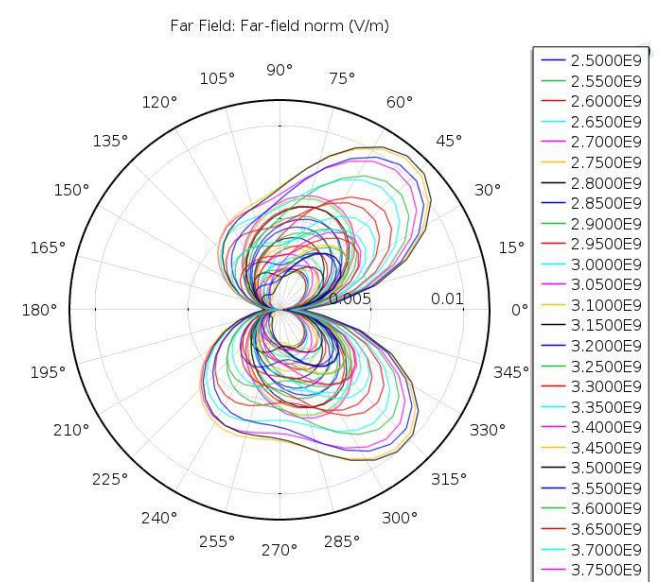

Figure 6: 2D radiation pattern for the proposed first antenna.

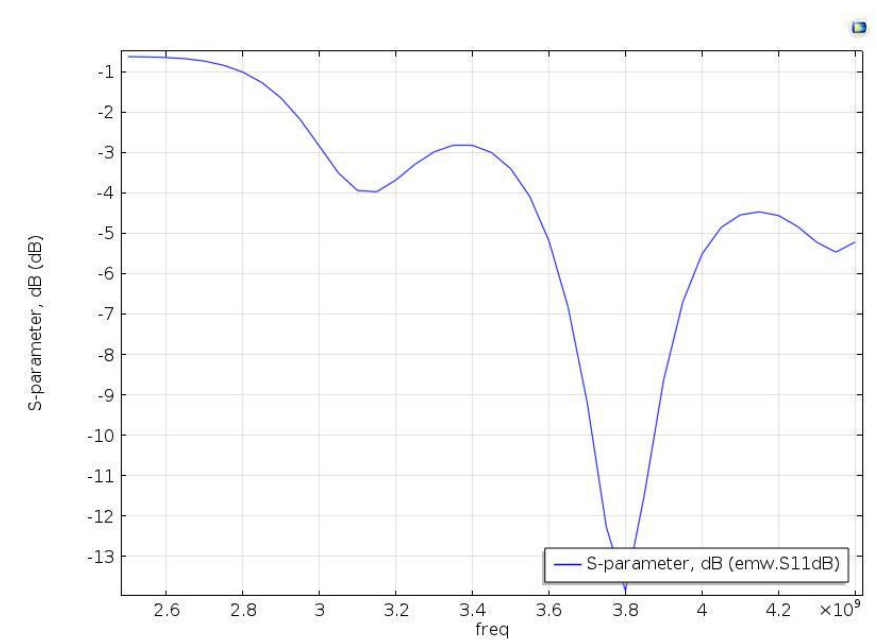

Figure 7: The frequency response of the first antenna. 


\section{AL-QADISIYAH JOURNAL FOR ENGINEERING SCIENCES}

Vol. 10 , No. 4

ISSN: $1998-4456$

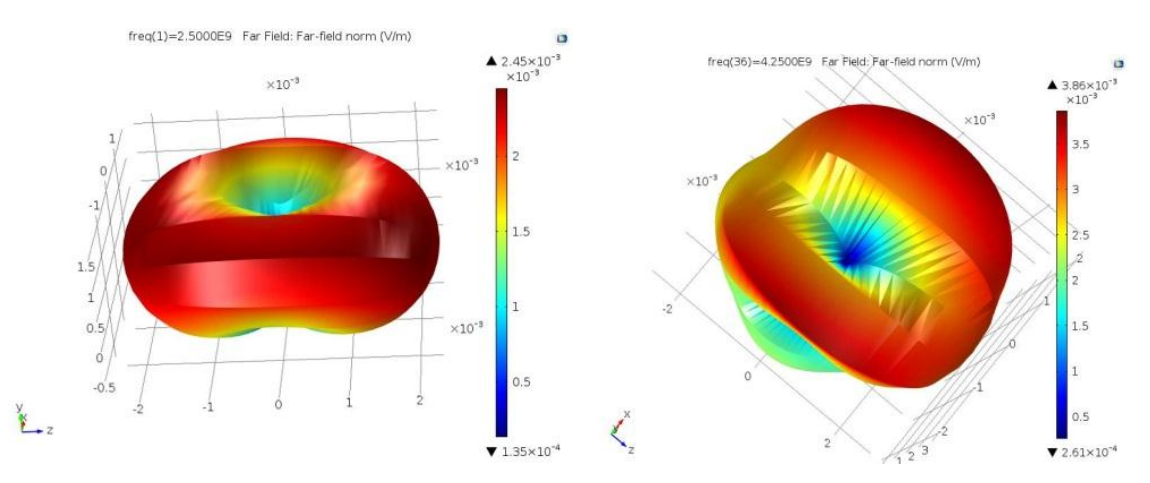

Figure 8: Far field norm of the first antenna.

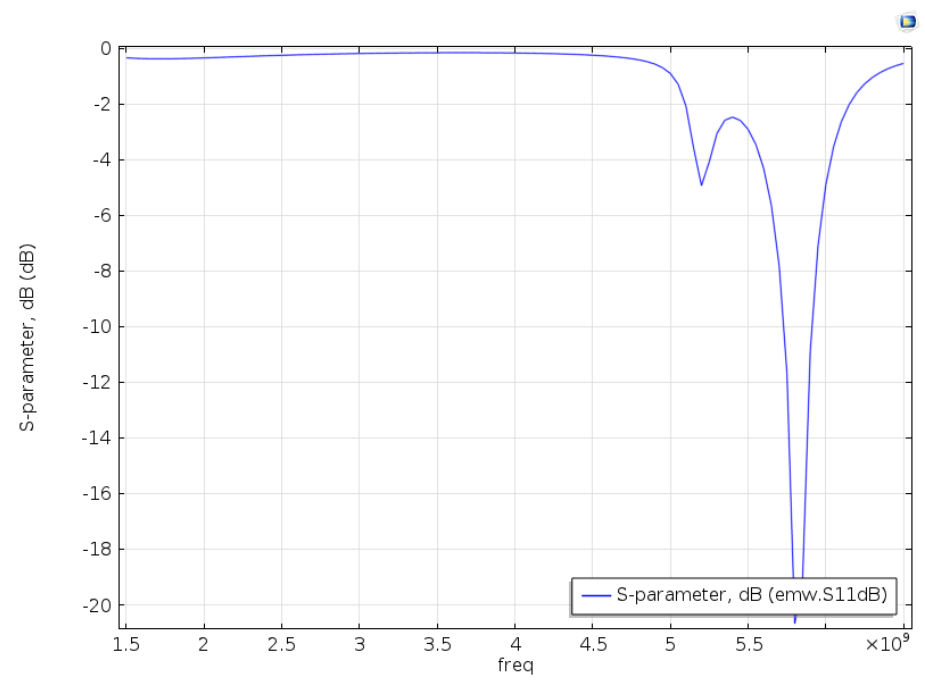

Figure 9: The insertions return losses response for the proposed second antenna.

\section{CONCLUSIONS}

A wearable microstrip antenna, with geometrical based on the button and square shapes introduced here. A patch antenna attained the desired frequency which used for child monitoring requirements. The antennas have been analysed by using COMSOL software. The outlet of the simulation indicated that the antennas possess a wideband resonant compatible and suitable frequencies for the requests of the 3.8 till $5.8 \mathrm{GHz}$. These bands cross with WBAN, WiFi, WiMax, and other wireless telecommunication systems. Performance of the most effective parameters of the antennas were considered.

From the results of antenna 1's simulation, it is found that the improved resonant frequency has shifted from $5.1 \mathrm{GHz}$ to $5.9 \mathrm{GHz}$ with same size and dimension of patch antenna. It shows the return loss less than of $-20 \mathrm{~dB}$ at $5.6 \mathrm{GHz}$ resonant frequency. For the antenna 2 the best resonant frequency is 3.8 with insertion loss equals to $-14 \mathrm{~dB}$. 


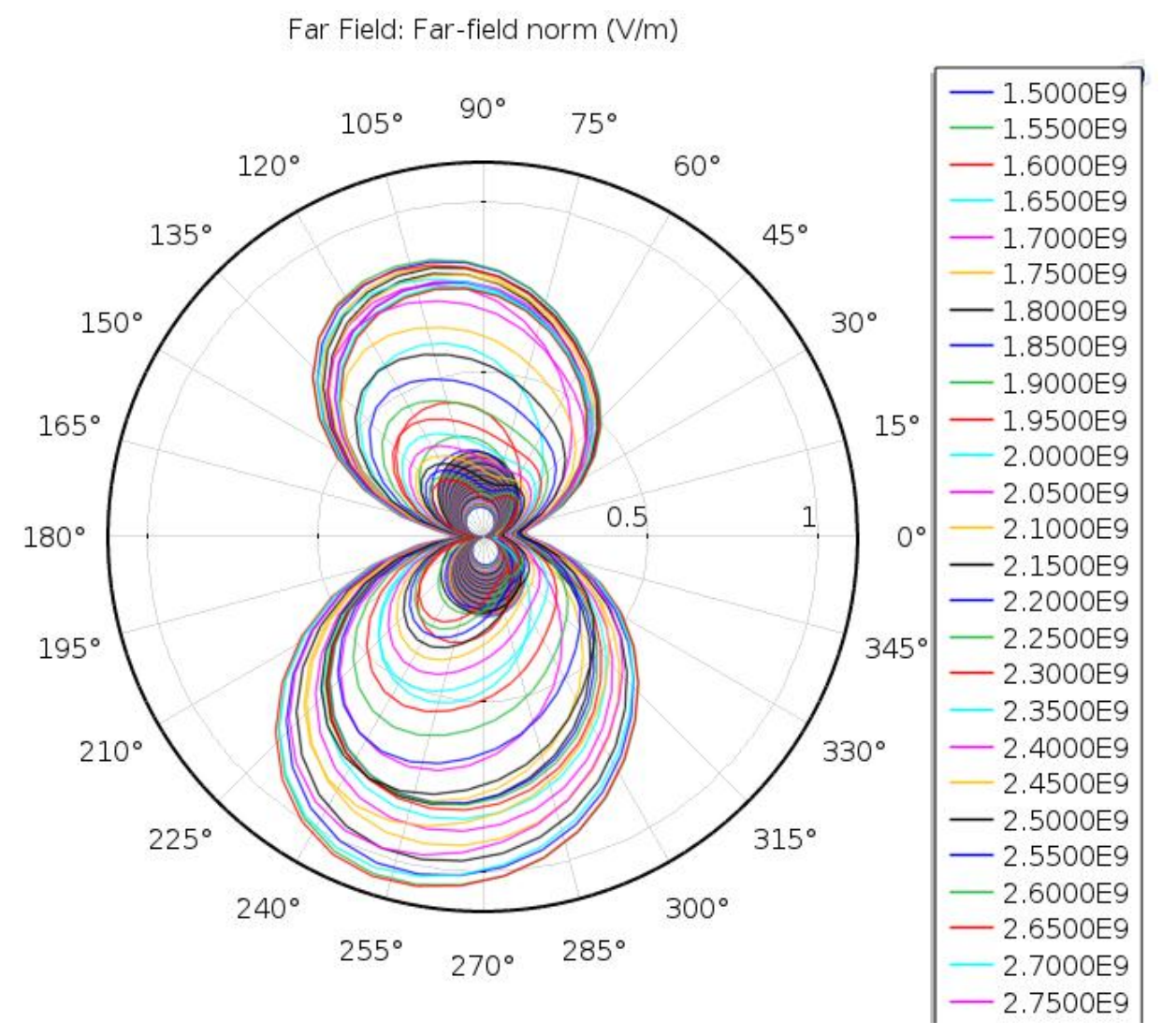

Figure10: Radiation pattern (2D) for the proposed first antenna at $5.6 \mathrm{GHz}$.

\section{REFERENCES}

1. Ahmed Ghanim Wadday and Hayder Jawad Albattat, "Design of Reconfigurable Microstrip Antenna with Wide Tunability Range for Cognitive Radio Network," Kufa Journal of Engineering, Vol. 7, No.2, 2016, pp. 1-8.

2. Ahmed Ghanim Wadday and Hayder Jawad Albattat, " Hidden Kuldo, Rotated Square and Kuldo Fractol Antenna of 2.4 to 5.4," Journal of Engineering and Sustainable Development, Vol. 20, No. 3, 2016, pp.47-59.

3. D. D. Cara, J. Trajkovikj, R. T. Sánchez, J. F. Zürcher, and A. K. Skrivervik, " A Low Profile UWB Antenna for Wearable Applications The Tripod Kettle Antenna (TKA)," IEEE, 7th Eu. Conf. on Antennas and Propagation , EuCAP , 2013, 3257-3260. 
4. K. Dwibedi, P. Patel, P. R, D Thiripurasundari and Z.C Alex, "Dual Band CPW Fed Wearable Monopole Antenna," IEEE, Proce. of Conference on Information and Communication Technologies, ICT 2013, pp. 1134-1137.

5. S. Sankaralingam, S. Dhar and B. Gupta, "Preliminary Studies on Performance of $2.45 \mathrm{GHz}$ Wearable Antenna in the Vicinity of Human," IEEE, International Conference on Communications, Devices and Intelligent Systems (CODIS), Kollkata, India, 2012, pp. 250-253.

6. Z. H. Jiang, D. E. Brocker, P. E. Sieber, and Douglas H. Werner, " A Compact, Low-Profile Metasurface-Enabled Antenna for Wearable Medical Body-Area Network Devices," IEEE Transactions on Antennas and Propagation, Vol. 62, No.8, August 2014, pp. $4021-4030$.

7. K. Agarwal1, Y.-X. Guo1, B. Salam and L. Ch. W. Albert, " Latex based Near End fire Wearable Antenna backed by AMC Surface," IEEE MTT-S International Microwave Workshop Series on RF and Wireless Technologies for Biomedical and Healthcare Applications (IMWS-BIO), 2013.

8. E. G. Lim, Z. Wang, J. Ch. Wang, M. Leach, R. Zhou, Ch. U. Lei and K. L. Man, "Wearable Textile Substrate Patch Antennas," Engineering Letters, May 2014. Pp. 94-101.

9. Effat O. EI Khashab and Hany F. Hammad, "A Size-reduced Wearable Antenna for Zigbee Indoor Localization," IEEE, Radio and Wireless Symposium (RWS), Santa Clara, CA, USA, Jan. 2012 pp. 95-98.

10. E. K. Kaivanto, M. Berg, E. Salonen, and P. D. Maagt ," Wearable Circularly Polarized Antenna for Personal Satellite Communication and Navigation," IEEE Trans. on Antennas and Propagation, Vol. 59, No.12, Dec., 2011, pp. 4490 - 4496. 